\title{
Eu:CROPIS - “Euglena gracilis: Combined Regenerative Organic-food Production in Space" - A Space Experiment Testing Biological Life Support Systems Under Lunar And Martian Gravity
}

\author{
Jens Hauslage ${ }^{1}$ D . Sebastian M. Strauch ${ }^{2}$. Olaf Eßmann ${ }^{3}$. Ferdinand W. M. Haag ${ }^{2} \cdot$ Peter Richter $^{3}$. Julia Krüger ${ }^{2}$. \\ Julia Stoltze ${ }^{2}$ - Ina Becker ${ }^{2}$ - Adeel Nasir ${ }^{2}$. Gerhild Bornemann ${ }^{1}$ • Hartmut Müller ${ }^{3}$ - Toni Delovski ${ }^{3}$. \\ Thomas Berger $^{1} \cdot$ Aleksandra Rutczynska $^{1} \cdot$ Karel Marsalek $^{1} \cdot$ Michael Lebert $^{2}$
}

Received: 7 August 2018 / Accepted: 7 September 2018 / Published online: 26 September 2018

(C) The Author(s) 2018, corrected publication 2018

\begin{abstract}
Human space exploration needs stable life support systems for the supply of oxygen, water and food for each human explorer due to long term missions. The most promising approach for building stable life support systems is a combination of physico-chemical and biological systems. These hybrid systems combine the reliability of physico-chemical and the sustainability of biological life support systems. Also the disadvantages, which are the finite resources of physico-chemical and the imperfect reliability of biological systems, are mutually balanced. To improve the reliability of biological life support systems, a combination of different biological systems may stabilize the whole approach during long term operations. The satellite mission Eu:CROPIS (Euglena gracilis: Combined Regenerative Organic-food Production In Space) is a testbed for investigating the behavior of combined biological life support systems under the influence of altered gravity, here, Lunar and Martian gravity. The core systems are a biological trickle filter for processing urine into a fertilizer solution via nitrification and Euglena gracilis, a photosynthetic protist which is able to produce oxygen and biomass while protecting the whole system against high ammonia concentrations.
\end{abstract}

Keywords Compact satellite $\cdot$ Life support system $\cdot$ Moon $\cdot$ Mars $\cdot$ Reduced gravity $\cdot$ Nitrification

\begin{tabular}{|c|c|c|c|c|}
\hline \multicolumn{3}{|c|}{ Abbreviations } & C.R.O.P.® & Combined Regenerative Organic-food \\
\hline \multicolumn{2}{|c|}{ ABS } & acrylonitrile butadiene styrene & & Production \\
\hline \multicolumn{2}{|c|}{ ACS } & attitude control system & DLR & German Aerospace Center \\
\hline \multirow{2}{*}{\multicolumn{2}{|c|}{ ATP }} & adenosintriphosphate, an energetic molecule & DNA & desoxyribonucleic acid \\
\hline & & for cell metabolism & GPS & global positioning system \\
\hline \multirow{2}{*}{\multicolumn{2}{|c|}{$\begin{array}{l}\text { BRLSS } \\
\text { cAMP }\end{array}$}} & biological regenerative life support systems & GSOC & German Space Operation Center \\
\hline & & cyclic adenosinmonophosphate, a messenger & HLSS & hybrid life support systems \\
\hline & & molecule & IF & interface \\
\hline \multicolumn{2}{|c|}{ CaM2 } & calmodulin 2 & ISS & International Space Station \\
\hline \multirow{2}{*}{\multicolumn{3}{|c|}{$\begin{array}{l}\square \text { Jens Hauslage } \\
\text { jens.hauslage@dlr.de }\end{array}$}} & MUSC & Microgravity User Support Center \\
\hline & & & PAM & pulse amplitude modulation \\
\hline & & & PAR & photosynthetic active radiation \\
\hline \multirow[t]{2}{*}{1} & \multirow{2}{*}{\multicolumn{2}{|c|}{$\begin{array}{l}\text { German Aerospace Center, Institute of Aerospace Medicine, } \\
\text { Linder Höhe, } 51147 \text { Cologne, Germany }\end{array}$}} & PCB & printed circuit board \\
\hline & & & PCLSS & physico-chemical life support \\
\hline \multirow[t]{2}{*}{2} & Cell B & gy Division, Gravitational Biology Group, & PDU & $\begin{array}{l}\text { systems } \\
\text { power distribution unit }\end{array}$ \\
\hline & Staud & sse 5, 91058 Erlangen, Germany & POM & polyoxymethylen \\
\hline 3 & $\begin{array}{l}\text { Germ } \\
\text { Rober }\end{array}$ & $\begin{array}{l}\text { erospace Center, Institute of Space Systems, } \\
\text { oke-Strasse 7, } 28359 \text { Bremen, Germany }\end{array}$ & $\begin{array}{l}\text { RAMIS } \\
\text { rpm }\end{array}$ & $\begin{array}{l}\text { RAdiation Measurment In Space } \\
\text { revolutions per minute }\end{array}$ \\
\hline
\end{tabular}




\section{Introduction}

Life support systems are mandatory for every closed habitat like space stations or Lunar and planetary outposts because it is virtually impossible to carry along sufficient supplies of water, food and oxygen needed during a long term space mission (Drysdale et al. 2003, 2004, Gitelson et al. 1995, Tikhomirov et al. 2007, Wieland 1998).

There are two different approaches for the implementation of life support systems, i.e., physico-chemical life support systems (PCLSS) and biological regenerative life support systems (BRLSS) (Bartsev et al. 2000; Czupalla et al. 2005; Mitchell 1994; Verostko et al. 1992). PCLSSs generate a desired product from an available source material by means of an appropriate physico-chemical reaction; often, there are byproducts generated which are not further used or even detrimental and consequently have to be discarded. Oxygen regeneration and carbon dioxide removal, e.g., can be achieved in a PCLSS by means of the Sabatier reaction with $\mathrm{H}_{2}$ from electrolysis of water, $\mathrm{T}>200^{\circ} \mathrm{C}$, and the use of an appropriate catalyzer e.g. nickel or ruthenium surfaces:

$$
\mathrm{CO}_{2}+4 \mathrm{H}_{2} \rightarrow \mathrm{CH}_{4}+2 \mathrm{H}_{2} \mathrm{O}
$$

$\mathrm{CH}_{4}+2 \mathrm{H}_{2} \mathrm{O} \rightarrow \mathrm{CH}_{4}+\mathrm{O}_{2}+2 \mathrm{H}_{2}$

The reaction requires high pressure and temperature, causing heavy and bulky reaction vessels. Methane is an end product with no direct use. In setups already in use on the International Space Station (ISS), $\mathrm{H}_{2}$ is extracted from water via electrolysis, generating additional $\mathrm{O}_{2}$ (Wieland 1998). Unfortunately, water is a relatively heavy commodity and it is expensive to transport it to the ISS. It has to be kept strictly contained and is lost in the process.

In BRLSSs the byproducts are mere intermediates for subsequent reactions. For example, oxygen production can be achieved via photosynthesis:

$6 \mathrm{CO}_{2}+6 \mathrm{H}_{2} \mathrm{O} \rightarrow \mathrm{C}_{6} \mathrm{H}_{12} \mathrm{O}_{6}+6 \mathrm{O}_{2}$

where $\mathrm{C}_{6} \mathrm{H}_{12} \mathrm{O}_{6}$ is a carbohydrate that can serve as food (Galston 1992). This reaction takes place at standard conditions. In fact, there is no PCLSS capable of generating any attractive form of nutrient matter; this can only be achieved via BRLSSs. As a desirable side effect, the water needed in (3) does not have to be as pure as for the use in an electrolyzer, and via transpiration the plant will humidify the environment. It can be recovered from the atmosphere by condensation and remains in the system.

BRLSSs mimic a natural ecosystem integrating the crew into a closed system, in which humans are the consumers, using oxygen and the biomass provided by plants or green (unicellular) algae, the producers (Binot et al. 1994; Wheeler 2006). In return, the carbon dioxide released by the humans is the carbon source for the plants.
The destruents, i.e., bacteria and fungi, break down the liquid and solid waste of the consumers and make the components available again for the producers, closing the circle. Simple ecosystems consist of only producers and destruents (Slenzka et al. 2000). The unique feature of a BRLSS, the production of fresh food, improves the diet of the astronauts and is a psychologically valuable counterbalance, as it brings some kind of "nature" to the technical environment of a space vessel (Freeman 2000; Haeuplik-Meusburger et al. 2014).

Compared to PCLSSs, BRLSSs are less reliable, as it is possible that unwanted organisms colonize and overgrow the system, which cannot occur in a PCLSS. The restart of a non-balanced system can be difficult and toxic substances might accumulate; however, problems also can occur in PCLSSs if a catalytic surface is contaminated or inhibitors of biological reactions enter the system, like heavy metals or plasticizers. The most ambitious objective in the field of life support systems is the closure of all elementary cycles, thereby allowing a fast and efficient way of recycling matter with a certain buffer capability.

On long term manned space missions, a combination of PCLSSs and BRLSSs as hybrid life support systems (HLSSs) promises synergetic effects: the reliability of the former might act as the support baseline, while the latter contributes to and enhances the overall performance (Gitelson et al. 1995). These hybrid systems can perform the nominal tasks by using BRLSSs. As safety backbone a system of PCLSSs will rescue the BRLSS in a case that one or more BRLSS components show a malfunction or deviate from the ecological balance. After returning to the nominal state, the BRLSSs can refill the PCLSSs with an overproduction of products like oxygen, plant fertilizer, fresh food and water etc. The aim of Eu:CROPIS beside the technical demonstration of a scientific platform for research under altered gravity is to investigate the function of combined regenerative biological life support systems: the capability to nitrify urine into a plant fertilizer solution and the production of oxygen and biomass under lunar and Martian gravity in a long term experiment (Fig. 1).

\section{Material and Methods}

\section{The C.R.O.P. ${ }^{\circledR}$ Microbial Filter and Euglena Gracilis}

A major challenge in manned space flight is the processing of urine (Salisbury et al. 1997). Presently, water is the only component recovered from it. All dissolved substances such as urea and salts are extracted and then discarded (Wieland 1998). In our approach, we follow the concept to use these valuable commodities and include them in a closed system to grow fresh fruits and vegetables after proper conversion. 


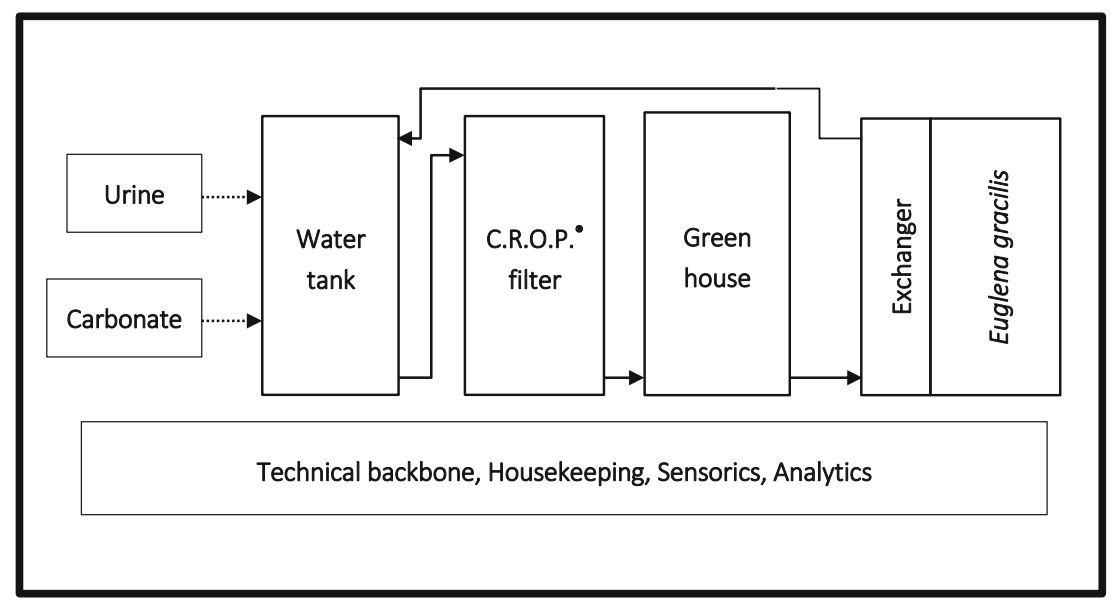

Fig. 1 Schematics of the Eu:CROPIS experiment. A closed loop of water flows from the water tank through the C.R.O.P.®-filter, the greenhouse and the exchanger back to the water tank. In the exchanger, a membrane confines Euglena to its compartment, while allowing the exchange of small molecules. Artificial urine and carbonate serve as

Currently, we perform extensive research on a system that produces a ready-to-use fertilizer solution for the cultivation of plants from urine, feces and biological waste (Bornemann et al. 2015, 2018; Verostko et al. 1992). The

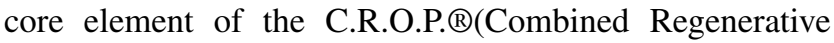
Organic-food Production) system is a microbiological trickle filter made from lava rock. A large number of different bacteria (Nitrosomonas, Nitrobacter, etc.) are able to find a habitat on the porous surface of the substrate in the C.R.O.P.®-filter. Some form biofilms in the aerobic zone on the immediate surface of the lava sediment; others live in small anaerobic cavities. Due to the large spectrum of microorganisms a wide range of biodegradable materials can be processed. The high degree of adaptability of this system with respect to organismic diversity allows its use for the degradation and detoxification of various substances passing through the filter tube. The filter is able to adjust dynamically to the substances by selective reproduction of the organisms that can degrade and utilize these substances as their food base (Bornemann et al. 2015, 2018).

Urea decomposes spontaneously to ammonia and $\mathrm{CO}_{2}$ :

$$
\begin{aligned}
& \mathrm{H}_{2} \mathrm{~N}-\mathrm{CO}-\mathrm{NH}_{2}+\mathrm{H}_{2} \mathrm{O} \rightarrow 2 \mathrm{NH}_{3}+\mathrm{CO}_{2} \\
& \mathrm{H}_{2} \mathrm{~N}-\mathrm{CO}-\mathrm{NH}_{2}+2 \mathrm{H}_{2} \mathrm{O} \rightarrow 2 \mathrm{NH}_{4}^{+}+\mathrm{CO}_{3}^{2-}
\end{aligned}
$$

The $\mathrm{pH}$ of the environment determines the ratio of reactions 4 and 5, so a pH-dependent ratio of $\mathrm{NH}_{3}$ and $\mathrm{NH}_{4}^{+}$ will occur.

The $\mathrm{NH}_{3} / \mathrm{NH}_{4}^{+}$will serve as an energy source for some of the bacteria in the C.R.O.P. ${ }^{\circledR}$-filter, and will be converted to nitrite and later nitrate. The oxygen necessary for that nitrogen and carbon sources both for the bacterial consortium in the filter column as well as the tomatoes in the greenhouse. To support the entire system, a technical backbone provides housekeeping, sensory and analytic data

reaction is initially provided by $E$. gracilis, and later on by the tomatoes (see below):

$$
\begin{aligned}
& 2 \mathrm{NH}_{3}+3 \mathrm{O}_{2} \rightarrow 2 \mathrm{NO}_{2}^{-}+2 \mathrm{H}^{+}+\mathrm{H}_{2} \mathrm{O} \\
& 2 \mathrm{NO}_{2}^{-}+\mathrm{O}_{2} \rightarrow 2 \mathrm{NO}_{3}^{-} \\
& \mathrm{NH}_{3}+2 \mathrm{O}_{2} \rightarrow \mathrm{NO}_{3}^{-}+\mathrm{H}^{+}+\mathrm{H}_{2} \mathrm{O}
\end{aligned}
$$

Higher plants like tomatoes prefer nitrate rather than ammonia or nitrite as a nitrogen source; moreover, ammonia and nitrite are toxic in high concentrations. The kinetics of the reactions will be monitored with an automated ion detection device in order to characterize the nitrogen cycle.

Results from our earlier experiments have shown that a bio-filter system like the C.R.O.P.®-filter is able to stabilize both an aquatic and a hydroponic plant system. The proposed Eu:CROPIS experiment takes advantage of this principle.

It is known that biofilms are affected by microgravity (McLean et al. 2001). The performance of the nitrification process in the trickle filter is dependent on the growth under microgravity and can be evaluated by the measured nitrification rate and the growth of tomatoes, which serve as bio-indicator.

All kinds of life support systems have to withstand space radiation and especially altered gravity during human space exploration (Wheeler et al. 2008). Away from Earth, humans, plants and other organisms are exposed to lower or no gravity, for example in habitats on Moon or Mars, or aboard a spacecraft. Gravity has always been and still is the only constant environmental factor during evolution on Earth, affecting the phylogenetic and individual development of all organisms, acting both as a 
factor of physical restriction and as an ubiquitous cue for orientation and postural control, thus comprising the gravitaxis of unicellular biosystems, the gravitropism of plants and the gravity sensing of multicellular animals (Morey-Holton 2003). Consequently, the knowledge of the impact of long term altered gravity on BRLSSs is mandatory for a successful human exploration.

The proposed Eu:CROPIS mission within the DLR compact satellite program offers for the first time the opportunity to analyze a BRLSS under different accelerations (Moon and Mars gravity) utilizing state of the art methods for the analysis of various biological and water parameters.

Euglena gracilis is a unicellular freshwater flagellate living in ponds and lakes worldwide. It uses gravity and light as stimuli to reach and stay in regions of the water column optimal for photosynthesis and growth. At low light irradiances, E. gracilis swims towards the light source, and at higher irradiances it moves away from it, a behavior referred to as positive and negative phototaxis, respectively (Lebert and Häder 2000). In addition, $E$. gracilis typically orients itself away from the center of acceleration (negative gravitaxis). Over the past 15 years, $E$. gracilis has been established as a model organism to study the gravity perception of single cells. A working hypothesis for gravitaxis was developed by means of physiological, biochemical and molecular biological methods (Daiker et al. 2011; Lebert et al. 1997; Richter et al. 2001a, 2002a; Streb et al. 2002). In this context, substantial contributions came from microgravity experiments carried out in space as well as in the course of sounding rocket flights and parabolic flight campaigns (Lebert et al. 1999; Nasir et al. 2014; Richter et al. 2001b, 2002b, 2007; Strauch et al. 2010; Tahedl et al. 1998).

According to the overall coherent and more focused working hypothesis, the gravity perception of E. gracilis is based on a difference between the specific density of the intracellular matter (cytoplasm and organelles like nucleus, chloroplasts, etc.) and the surrounding environment (Lebert and Häder 1996). This leads to the sedimentation of cell contents within the cell body, which is contained by the cytoplasmic membrane. The sedimentation exerts a force on the lower membrane and thereby activates mechanosensitive channels embedded in the membrane (Häder et al. 2006a). This leads to a massive influx of calcium into the cell, which then binds to a protein (CaM2). CaM2 in turn activates an adenylate cyclase which produces cAMP, a second messenger, from ATP. The increased cAMP concentration results in a modified stroke rhythm of the flagellum, the organelle responsible for the locomotion of the cell (Ntefidou et al. 2003).

In parallel with these studies on graviperception of $E$. gracilis, the organism was established as an integral element of biological life support systems. Following an initial

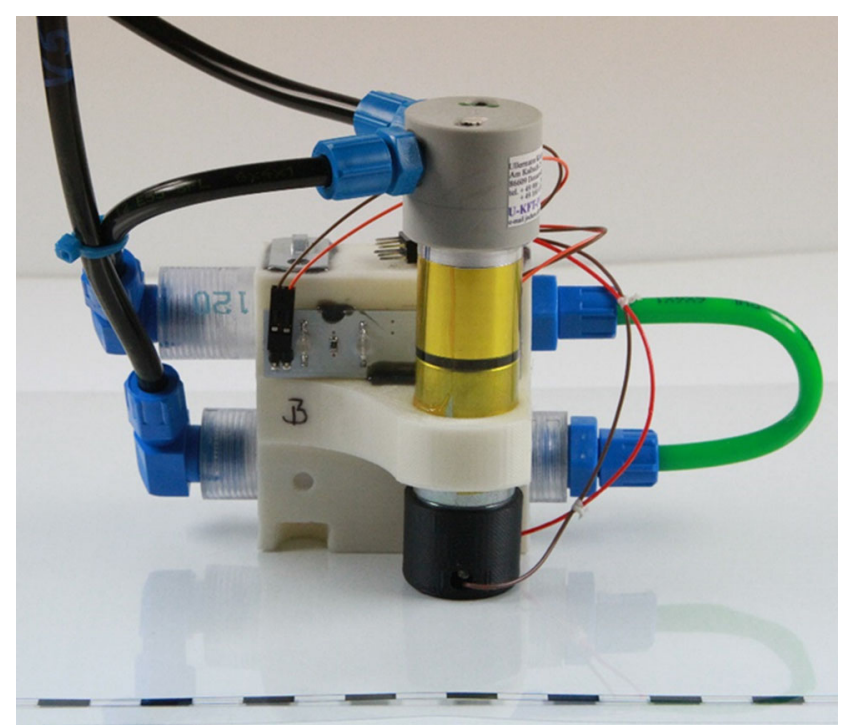

Fig. 2 Dormant mode container. The upper polycarbonate tube contains dormant $E$. gracilis cells, the lower one a mixture of nutrients. The vertical component is the pump, behind it the illumination board. The main body of the dormant container was produced by fused deposition modeling using acrylonitrile butadiene styrene (ABS). Scale segments are $10 \mathrm{~mm}$ long

experiment in 2003 (Häder et al. 2006b), a coupled algaebacteria-fish system flew on the Foton-M3 satellite for two weeks (Strauch et al. 2008; Strauch 2009). The experiment was extremely successful and served as the foundation for a similar experiment on the BION-M1 satellite.

In unfavorable conditions, E. gracilis forms dormant states and can survive cold and dry periods. In natural conditions, this occurs in winter or in dry, hot summers. We developed a protocol to transfer E. gracilis cultures reliably into dormant states (Strauch et al. 2017) and "wake them up" on demand after up to 12 months (Fig. 2). This was necessary in order to bridge the time between integration of the experiment into the satellite and the start of the experiment in orbit.

\section{General Description of Eu:CROPIS}

Eu:CROPIS (Euglena gracilis: Combined Regenerative Organic-food Production In Space) is the name of both a compact satellite and its primary payload. The task of $E$. gracilis in Eu:CROPIS is to provide the C.R.O.P.®-filter with the oxygen necessary for the conversion of urine to nitrate until the photosynthetic oxygen production by the tomatoes is sufficient. In contrast to the tomatoes, E. gracilis favors ammonia over nitrate, which avoids any competition for the $\mathrm{N}$-source. The cells will also lessen the impact of ammonia after urine injection, protecting the seedlings from excessive toxic ammonia levels. 


\section{Principal Configuration of Eu:CROPIS}

After the satellite will have reached its orbit and achieved the desired rotation speed, the first experiment in payload one will start: valves will open a closed loop, and pumps will rinse dormant cells of $E$. gracilis into a two-compartment tank, where the cells will grow to a photosynthetically active culture. After reaching a certain cell density, which will be determined by measuring the scattering in the culture liquid, the valves will separate the two compartments, which are identical in all respects except the position within the payload: one tank is located on the reference radius, the other one is placed closer to the rotational axis, resulting in different mean acceleration levels within the water column of each tank. Therefore, during the first phase with lunar gravity at the reference radius, the inner tank will perform a $\mu$-gravity experiment, while during Mars gravity on the reference radius, the inner tank will do a replica of the Moon gravity experiment.

When the Euglena cultures have sufficiently grown, a different set of valves will open a second closed loop: water from a water tank will be pumped through an exchanger coupled with the Euglena tanks and then to the C.R.O.P. ${ }^{\circledR}$ filter (Fig. 1). Then, another pump will pump it into a small greenhouse with six tomato seeds. The cycle will be closed when the water is pumped again into the water tank. As there is no consumer in Eu:CROPIS, but just producers and destruents, artificial urine (Feng and Wu 2006) will serve as nitrogen source, and carbonate as carbon source. Both solutions will be periodically injected into the water tank.

\section{The Water Tank}

The system has to be dry between integration and begin of the experimental phase in orbit. The water tank is the main water reservoir during that time and has a volume of four liters. It is milled out of polycarbonate and shaped like a torus segment with a square cross section. As a secondary function, the filled water tank serves as a nutation damper for the satellite. Consequently, it is located on the outer perimeter of the payload and equipped with 3D-printed baffles. It is equipped with four temperature sensors to monitor water temperature during and before flight, three level sensors and one $\mathrm{pH}$ and oxygen patch for fluorometric determination of the respective values.

\section{The C.R.O.P. ${ }^{\circledR}$-Filter}

The C.R.O.P.®-filter container (approx. volume $400 \mathrm{ml}$ ), is made of polycarbonate. To protect it from abrasive forces during transport and launch, a layer of fiberglass roving separates the lava rocks from the walls. Close to the outlet, oxygen and $\mathrm{pH}$ sensor spots are placed, as the $\mathrm{pH}$ value is crucial for the determination of the $\mathrm{NH}_{3} / \mathrm{NH}_{4}^{+}$ratio of the filter effluent.

\section{The Greenhouse}

The greenhouse is made of polycarbonate; the volume is approximately $12 \mathrm{~L}$. The sensory equipment comprises of two level sensors and two substrate moisture sensors (Maier and Kamm 2017) to check for water presence, six temperature sensors and a humidity sensor to characterize the atmosphere. Four fans create airflow over an aluminummilled cooler thermally connected to the ground plate to precipitate excess humidity from the air and to cool it down. Atop the greenhouse, three illumination panels provide light for photosynthesis and monitoring of the tomatoes. Each panel not only contains regulated illumination with up to $24 \mathrm{~W}$ with a PAR value of approx. $280-350 \mu \mathrm{mol} \mathrm{m}^{-2} \mathrm{~s}^{-1}$, but also two sensors to measure photosynthetic yield via pulse amplitude modulation (PAM) fluorometry and two cameras for top view. Additionally 10 cameras around the greenhouse provide lateral images of the plants.

\section{The Euglena Gracilis Tank}

The E. gracilis tank and the exchanger are made of polycarbonate. Each compartment contains ca. $700 \mathrm{~mL}$ of distilled water in the beginning. One illumination panel per compartment provides red and blue light for photosynthesis, IR illumination for line scanners to measure cell density over the entire height of the compartment, and two PAM-fluorometers to determine the photosynthetic yield. Furthermore, each compartment is equipped with an oxygen and $\mathrm{pH}$ sensor spot.

\section{Other "Wet" Components}

The connective tubing is made with polyamide hoses and POM connectors.

Three custom-made cogwheel pumps run each of the two redundant loops in parallel. To verify correct pumping, flow sensors are located between the water tank and the greenhouse, the greenhouse and the exchanger, and the exchanger and the water tank. To counteract a blockage of sensors and keep a redundant flow system, only one of two parallel loops is equipped with them. In a case of a blockage, the second set of pumps will take over and the flow information will be lost.

The dormant mode containers are made of polycarbonate (Fig. 2) tubes and housed in a 3D-printed mount. An attached printed circuit board provides a minute amount of light for the survival of the cells in one of the tubes produced by white LEDs. The other one contains nutrients. The pump for the inoculation of the culture is mounted on it as well. 
As part of the late access procedures, the complete units will be changed 3 months prior to launch.

Two arrays of valves confine the water to the water tank and the exchanger until the experiment starts. The smaller array contains two pairs of redundant valves to block the water loop before the exchanger and after the water tank. The bigger array with six valves connects the Euglena compartments with each other and the dormant mode containers and divides the Euglena culture in two after the inoculation phase.

\section{Electronics}

The electronic system of the primary payload has two major functions: it has to control vital functions like illumination, irrigation and heat management, and it has to collect data from all the attached sensors and cameras, process them and pass them on to the onboard computer for transmission to ground. The basis of the electronic hardware is a commercially available development board with printed circuit boards (PCBs) piggy-backed on top to accommodate the peripherals: the module controller, the power distribution unit (PDU), and the communications board, all connected via RS422 communications bus. The module controller is connected to most of the sensors (temperature, oxygen, g-level at the reference radius, humidity etc.) and also to the illumination boards of the greenhouse and the E. gracilis tank, and the expression analysis device. The PDU switches peripherals, and collects data form the ion detection device and the internal radiation measurement unit RAMIS (RAdiation Measurement In Space).

A dedicated power supply unit provides $12 \mathrm{~V}$ throughout each payload module. It is based on an MGDM-200O-E with filtering units.

Crucial components were tested beforehand to make sure they are resistant to expected vibrations and radiation over the mission period.

\section{Ion Detection}

In order to verify the suitability of the C.R.O.P.®-filter system for the assigned task within the experiment, the conversion rates of the different nitrogen species have to be monitored and quantified. A commercially available system was adapted in order to fit constrains regarding available space and robustness. It is equipped with seven half-cell electrodes to measure ammonium, nitrite, nitrate, $\mathrm{pH}$, chloride, sodium, and potassium. The electronics were adapted to fit into the existing hardware framework. A set of calibration solutions is integrated inside the ion detection to verify the measurement values in fixed periods.

\section{Expression Analysis}

In order to identify proteins involved in the graviorientation of $E$. gracilis, we want to monitor the expression pattern. In brief: proteins are encoded in the DNA (deoxyribonucleic acid) of an organism. If a protein is to be synthesized, its DNA code is transcribed into mRNA (messenger ribonucleic acid) in the nucleus of the cell. The mRNA is then exported into the cytoplasm and guided to ribosomes. Here, the mRNA code is translated into the corresponding protein. By capturing and analyzing the entire mRNA of a cell, it is possible to make assumptions about the demand of proteins in the cell. For that, we use magnetic beads to bind the mRNA after lysis of a cell sample. Then, the mRNA is re-transcribed into DNA with modified nucleotides (the building blocks of DNA). The resulting string of DNA is fluorescent. The DNA solution, which contains now the code of all the mRNA that was present in the cell at the time of lysis, is then applied on a chip array, which in turn contains probes with DNA sequences of interest. The fluorescing string of DNA will bind to their corresponding probes and generate a signal: the brighter the spot, the more mRNA of that code was present in the cell. Extensive studies were taken in order to assure a long enough shelf-life of the chemicals involved in the analysis (Becker et al. 2017).

\section{Radiometry}

The RAMIS detector developed at the Institute of Aerospace Medicine at DLR will measure the radiation environment during the mission. To this end, two identical RAMIS detectors were built. The first one is mounted at the top surface of the satellite under very low shielding (which is only provided by the aluminum casing of the detector itself (Fig. 3). The second one is positioned as a sensor for the primary payload hardware and will provide radiation quantities and dosimetry for the biological samples.

RAMIS (RAdiation Measurement In Space) uses an arrangement of two silicon detectors in telescope geometry, and enables to investigate the following scientific objectives. The first aim will be on the exact determination of the fluxes of protons and electrons in the Earth's radiation belts. Those data will serve as input for the validation and benchmarking of current radiation field models and in addition for further model development. As a second aim the experiment will determine the variation of the galactic cosmic ray contribution to the radiation field by measuring the relevant parameters in dependence of the orbit of the satellite. In a next step, analyzing the data gathered for the radiation field parameters, the experiment will also provide the relevant quantities for radiation dosimetry as the absorbed dose, the energy deposition spectra and the relevant dose equivalent. 


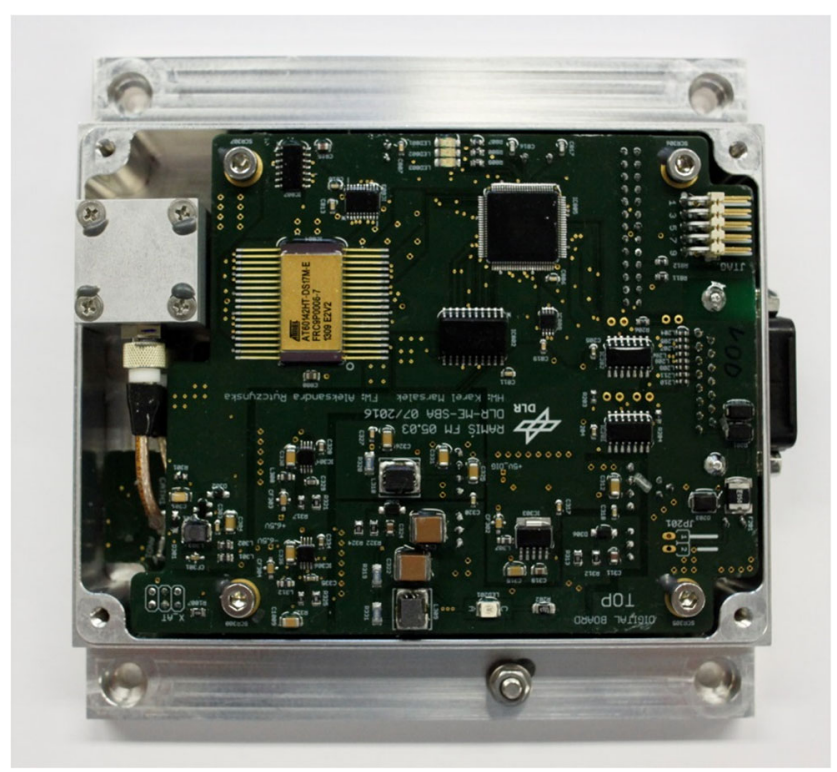

Fig. 3 The Radiation Measurements In Space (RAMIS) Flight Model (FM) detector with open lid showing in the top left part the silicon detector telescope as well as the digital PCB board with the relevant digital electronics. The analogue board with relevant preamplifiers and analogue electronics is below the digital board. In addition one can see on the right part of the outer surface the power and data connector for connection to the Eu:Cropis satellite. Size approx. width $14 \mathrm{~cm} \mathrm{x}$ length $14 \mathrm{~cm} \times$ height $4 \mathrm{~cm}$

\section{Spacecraft and Mission}

The Eu:CROPIS experiment is the primary payload of a DLR CompactSat spacecraft. The DLR CompactSat is a highly adaptable satellite bus with a weight limit of $250 \mathrm{~kg}$. The volume envelope is limited to approximately one cubic meter. Therefore, the spacecraft is ranked at the lower end of the mini satellite class. The primary purpose of the DLR CompactSat is to promote a freely accessible space based platform for research and development.

The satellite has no specific default configuration. Instead, each satellite will be individually developed according to the requirements of the respective payload by using standard components and mission/payload specific adaptions and solutions. The objective is an optimal configuration to implement the given aspiration in a cost and time efficient manner. Under these guidelines, the configuration of each DLR CompactSat will be based substantially on the payload requirements and may vary extremely depending on the respective mission.

Biological life support systems incorporate plants and microorganisms with certain conditions regarding temperature and pressure. This is why the payload is housed in a pressurized vessel. The vessel, a DLR technology development, is made of carbon fiber reinforced plastics and part of a micrometeorite shielding. This shielding has three layers.
The first layer is the aluminum outer hull of the satellite. The second layer is an aramid fabric and the third layer is the pressure vessel itself. During testing, the system was found suitable for protection against micrometeorites up to $1 \mathrm{~mm}$ in size, which constitutes approximately $99 \%$ of the associated risk.

Another basic requirement is the establishment of different levels of artificial gravity, which is an experiment parameter. This is done by rotation. Consequently, the satellite features a spin stabilized design, rather than a 3axes stabilization. It is able to establish any rotation rate between 1 and $32 \mathrm{rpm}$, the latter resulting to approximately $0.38 \mathrm{x} \mathrm{g}$ (gravity of Mars) at a radius of $350 \mathrm{~mm}$. Responsible for the establishment of the rotation rates as well as the attitude control in general is the attitude control system (ACS), which features magnetic torquers, magnetometers, fiber optical rate gyros and sun sensors.

The payloads temperature requirements have tighter limits than the mechanics and electronics of the bus. Nevertheless it was possible to meet these requirements with a (semi-)passive temperature control system (no active cooling), which features only very few emergency heaters. The temperature control system works in connection with the satellites operations, making use of the heat dissipation of the different subsystems and units in on and off state.

Electrical power is provided by 4 deployable solar panels with a total nominal power of $756 \mathrm{~W}$. It is distributed via a $28 \mathrm{~V}$ unregulated power bus and buffered by an onboard battery with an energy capacity of $1024 \mathrm{Wh}$.

The spacecraft is able to operate autonomously for at least $48 \mathrm{~h}$. The onboard computer provides a corresponding amount of mass memory. The expected daily data volume will be approximately $120 \mathrm{MB}$ and the daily downlink capacity is $160 \mathrm{MB}$ in the S-Band regime.

Finally, a GPS system provides time and position, three outside cameras give general purpose status information and there are three additional secondary payloads, each of them featuring their own science case (Figs. 4 and 5).

The satellite will be placed in a sun synchronous orbit at an altitude of $575 \mathrm{~km}$. A sun synchronous orbit is a special type of low earth orbit. It is highly inclined and the orbital plane is rotating slowly $\left(360^{\circ}\right.$ per annum) due to the inhomogeneity of the Earth's gravity field. Thus, the direction to the sun is constant. The spinning spacecraft will be pointing at the sun for power maximization. The mission is planned to take $15-18$ months. The maximum duration was determined to be 24 months.

The satellite operations will be carried out by the German Space Operations Center (GSOC) in Oberpfaffenhofen (Germany). The primary ground station will be the facility in Weilheim, Germany. GSOC is working in close connection with the microgravity user support center (MUSC) 


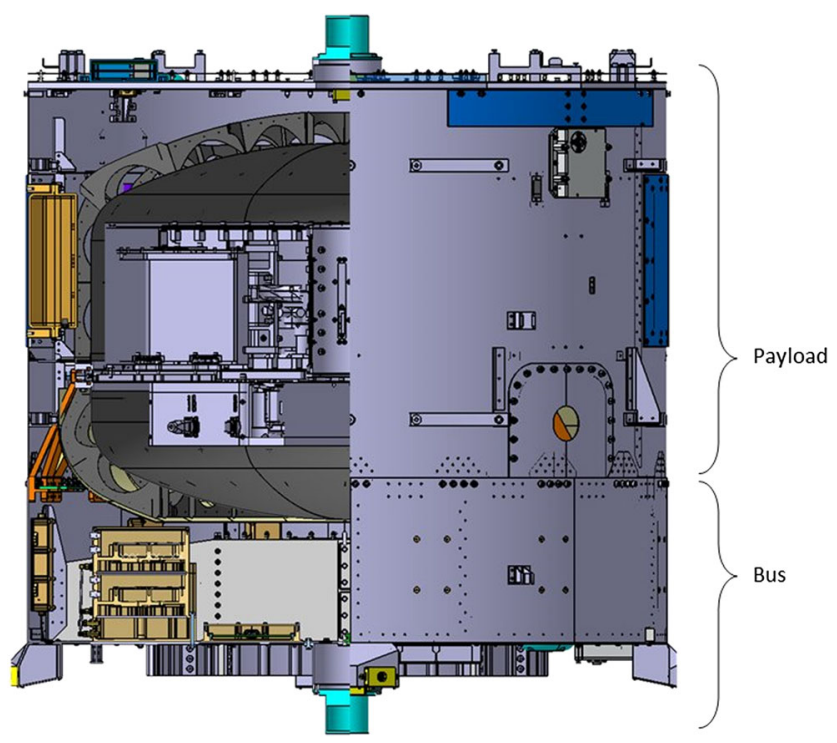

Fig. 4 Schematics of the Eu:CROPIS spacecraft. Inside view (left), outside view (right). Solar panels are not depicted. The lower part shows the bus compartment. In the upper part, the primary payload is located inside the pressurized vessel. The outer hull and the top plate of the satellite also belong to the satellite bus. They carry additional bus units and secondary payloads

in Cologne, Germany, which will provide the interface to GSOC for telemetry and telecommand. It will also provide the data pick-up point for the investigators and is responsible for the data archive.

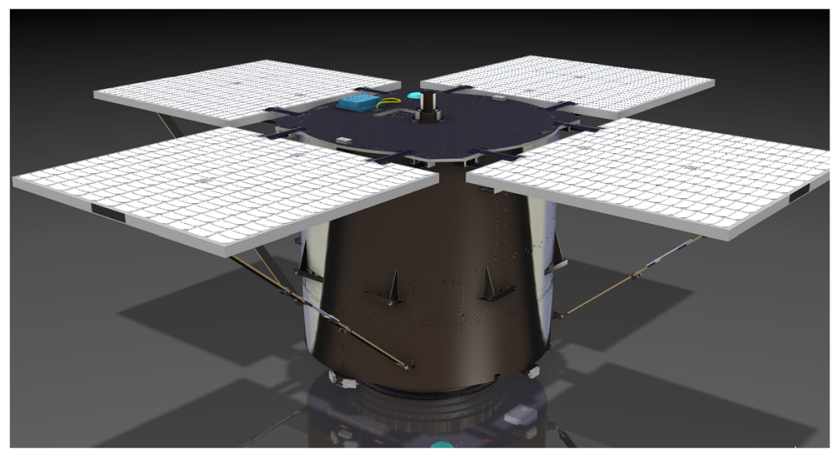

Fig. 5 The Eu:CROPIS spacecraft in flight configuration with deployed solar panels. The satellite is a cylindrical container (approximately $1 \mathrm{~m}$ diameter x $1 \mathrm{~m}$ height, size of the solar panels approx.. $1 \mathrm{~m} \times 1 \mathrm{~m}$ ) with four solar panels. In orbit, the top side will face the sun, and it will rotate to achieve altered gravity levels within the payload: after a spin-up phase of several weeks, it will reach about $20.5 \mathrm{rpm}$ and generate an acceleration force of $0.16 \mathrm{x}$ g on the reference radius, which equals the acceleration on the surface of the Moon. The first set of the payload segment will start the experiment. After 6 months of lunar gravity, the experiment will be terminated. The satellite will ramp up its rotation rate to achieve $31.6 \mathrm{rpm}$, generating $0.38 \mathrm{x} \mathrm{g}$ on the reference radius, which is the acceleration on Mars. The second set of the payload segment will be switched on, and the experiment will take place in exactly the same way under a different gravity level

\section{Summary and Outlook}

Hybrid life support systems are the basis of a successful human long term space exploration. The current research of hybrid life support systems is in the beginning with the aim to understand all the interactions of life support subsystems. Also, combined biological life support systems are not well understood yet. Eu:CROPIS will be the first experiment in which a combined biological life support system will be investigated under Lunar and Martian gravity conditions. Gaining more knowledge for future planning and the construction of sustainable combined biological life support systems should be the primary goal for life support research. Results obtained from the Eu:CROPIS will also help to solve problems on Earth:

The reduction of waste is a crucial point in times of growing Mega-Cities and increasing populations (Fuchs et al. 1999). C.R.O.P. ${ }^{\circledR}$ contributes by reducing biodegradable waste and offers a possibility to grow vegetables and even animal protein in apartment spaces (Bornemann et al. 2015). Additionally, the system enhances air quality by cleansing and humidifying the atmosphere. Facilities following the principles of C.R.O.P. ${ }^{\circledR}$ in agriculture will diminish the amount of organic residues and pre-processed fertilizing solutions.

The detoxification effect, however, is yet not well understood. It can be assumed that especially the anaerobic bacteria could be able to utilize complex molecule, like polyaromatics, hormones and antibiotics. First results in detoxification experiments have shown that xenobiotica like Ibuprofen is degraded over $90 \%$ (data not shown). This will play a crucial role in the future development of life support systems to remove all toxic or health influencing substances which are back up in the element cycles like water and air in closed loop systems.

Future space missions will require resource-efficient and reliable habitat and energy systems. In general, recycling processes are of major importance to allow an effective performance.

The Eu:CROPIS mission will be a further step in the understanding of combined biological life support system, emphasizing the biological component comprising two loops (E. gracilis and higher plants) under altered gravity in a long duration experiment. Results from this experiment can be used in the further design of bioregenerative life support in crewed exploration missions as well as on lunar or planetary bases.

Eu:CROPIS is also a precursor mission for the usage of "of the shelf" compartments in contrast to the expensive space industry hardware to build a gravitational space experiment. Dealing with the reliability and the occurrence of failures is no option in the field of life support when humans are involved but should be considered 
by the investigation of basic research with biological model organisms in space experiments. This will speed up the development, reduce costs and allow to gain more scientific results in a shorter time. Eu:CROPIS triggered the development of novel instruments like the compact ion detection device, the expression analysis device and the capacitive soil moisture sensors and extensively used innovative production methods as fused deposition modeling for structural elements in space flight experiments.

Eu:CROPIS grants insight into an ecosystem with gravity smaller than on Earth, and gives an opportunity to learn how such a small force shapes life. Expected results can show how the closed cycles, which form the basis of all ecosystems on Earth, go faster or slower, as the reduced physical force interacts with key biological parameters like the conversion rates in the metabolism of the microorganisms involved. Thus, Eu:CROPIS offers a unique possibility to better understand life on Earth developed under $1 \mathrm{~g}$.

Acknowledgements The Eu:CROPIS project was funded by the German Aerospace Center in the frame of the compact satellite program.

Open Access This article is distributed under the terms of the Creative Commons Attribution 4.0 International License (http://creativecommons. org/licenses/by/4.0/), which permits unrestricted use, distribution, and reproduction in any medium, provided you give appropriate credit to the original author(s) and the source, provide a link to the Creative Commons license, and indicate if changes were made.

\section{References}

Bartsev, S.I., Mezhevikin, V.V., Okhonin, V.A.: Evaluation of optimal configuration of hybrid life support system for space. Adv. Space Res. 26(2), 323-6 (2000)

Becker, I., Strauch, S.M., Hauslage, J., Lebert, M.: Long term stability of Oligo (dT) 25 magnetic beads for the expression analysis of Euglena gracilis for long term space projects. Life Sci. Space Res. 13, 12-8 (2017)

Binot, R.A., Tamponnet, C., Lasseur, C.: Biological life support for manned missions by ESA. Adv. Space Res. 14(11), 71-4 (1994)

Bornemann, G., Waßer, K., Tonat, T., Moeller, R., Bohmeier, M., Hauslage, J.: Natural microbial populations in a water-based biowaste management system for space life support. Life Sci. Space Res. 7, 39-52 (2015)

Bornemann, G., Waßer, K., Hauslage, J.: The influence of nitrogen concentration and precipitation on fertilizer production from urine using a trickling filter. Life Sci. Space Res. 18, 12-20 (2018)

Czupalla, M., Horneck, G., Blome, H.J.: The conceptual design of a hybrid life support system based on the evaluation and comparison of terrestrial testbeds. Adv. Space Res. 35(9), 1609-20 (2005)

Daiker, V., Häder, D.-P., Richter, P.R., Lebert, M.: The involvement of a protein kinase in phototaxis and gravitaxis of Euglena gracilis. Planta. 233(5), 1055-62 (2011)
Drysdale, A.E., Ewert, M.K., Hanford, A.J.: Life support approaches for Mars missions. Adv. Space Res. 31(1), 51-61 (2003)

Drysdale, A.E., Rutkze, C.J., Albright, L.D., LaDue, R.L.: The minimal cost of life in space. Adv. Space Res. 34(7), 1502-8 (2004)

Feng, D.L., Wu, Z.C.: Culture of Spirulina platensis in human urine for biomass production and $\mathrm{O}(2)$ evolution. J. Zhejiang Univ. Sci. 7(1), 34-7 (2006)

Freeman, M.: Challenges of human space exploration: Springer Science \& Business Media (2000)

Fuchs, R.J., Brennan, E., Chamie, J.: Mega City Growth and the Future. United Nations University Press, Tokyo (1999)

Galston, A.W.: Photosynthesis as a basis for life support on earth and in space. BioScience 42(7), 490-3 (1992)

Gitelson, J.I., Blum, V., Grigoriev, A.I., Lisovsky, G.M., Manukovsky, N.S., Sinyak, Y.E., Ushakova, S.A.: Biological-physical-chemical aspects of a human life support system for a lunar base. Acta. Astronaut. 37, 385-94 (1995)

Häder, D.-P., Richter, P.R., Lebert, M.: Signal transduction in gravisensing of flagellates. Signal Transduct. 6(6), 422-31 (2006a)

Häder, D.-P., Richter, P.R., Strauch, S.M., Schuster, M.: Aquacells flagellates under long term microgravity and potential usage for life support systems. Micrograv. Sci. Technol. 18, 210-4 (2006b)

Haeuplik-Meusburger, S., Paterson, C., Schubert, D., Zabel, P.: Greenhouses and their humanizing synergies. Acta Astronaut. 96, 138-50 (2014)

Lebert, M., Häder, D.-P.: How Euglena tells up from down. Nat. 379(6566), 590 (1996)

Lebert, M., Häder, D.-P.: Photoperception and phototaxis in flagellated algae. Res. Adv. Photochem. Photobiol. 1, 201-26 (2000)

Lebert, M., Porst, M., Richter, P., Häder, D.-P.: Physical Characterization of Gravitaxis in Euglena gracilis. J. Plant. Physiol. 155(3), 338-43 (1999)

Lebert, M., Richter, P., Häder, D.-P.: Signal perception and transduction of gravitaxis in the flagellate Euglena gracilis. J. Plant. Physiol. 150, 685-90 (1997)

Maier, T., Kamm, L.: Moisture sensor for gravitation dependent plant watering. In: International Astronautical Federation, 68. International Astronautical Congress Adelaide 1-7 (2017)

McLean, R.J.C., Cassanto, J.M., Barnes, M.B., Koo, J.H.: Bacterial biofilm formation under microgravity conditions. FEMS Microbiol. Lett. 195(2), 115-9 (2001)

Mitchell, C.A.: Bioregenerative life-support systems. Am. J. Clin. Nutr. 60(5), 820S-824S (1994)

Morey-Holton, E.R.: The Impact of Gravity on Life. In: Evolution on Planet Earth: Elsevier 143-159 (2003)

Nasir, A., Strauch, S.M., Becker, I., Sperling, A., Schuster, M., Richter, P.R.: The influence of microgravity on Euglena gracilis as studied on Shenzhou 8. Plant Biol. 16 Suppl. 1, 113-9 (2014)

Ntefidou, M., Iseki, M., Watanabe, M., Lebert, M., Häder, D.P.: Photoactivated adenylyl cyclase controls phototaxis in the flagellate Euglena gracilis. Plant Physiol. 133(4), 1517-21 (2003)

Richter, P., Lebert, M., Korn, R., Häder, D.-P.: Possible involvement of the membrane potential in the gravitactic orientation of Euglena gracilis. J. Plant Physiol. 158, 35-9 (2001a)

Richter, P.R., Lebert, M., Tahedl, H., Häder, D.-P.: Physiological characterization of gravitaxis in Euglena gracilis and Astasia longa studied on sounding rocket flights. Adv. Space Res. 27, 983-8 (2001b)

Richter, P.R., Ntefidou, M., Streb, C., Lebert, M., Häder, D.-P.: Physiological characterization of gravitaxis in Euglena gracilis. J. Gravitat. Physiol. 9, 279-80 (2002a)

Richter, P.R., Schuster, M., Wagner, H., Lebert, M., Häder, D.-P.: Physiological parameters of gravitaxis in the flagellate Euglena 
gracilis obtained during a parabolic flight campaign. J. Plant Physiol. 159, 181-90 (2002b)

Richter, P.R., Schuster, M., Lebert, M., Streb, C., Häder, D.-P.: Gravitaxis of Euglena gracilis depends only partially on passive buoyancy. Adv. Space Res. 39(7), 1218-24 (2007)

Salisbury, F.B., Gitelson, J.I., Lisovsky, G.M.: Bios-3: Siberian experiments in bioregenerative life support. BioScience 47(9), 575-85 (1997)

Slenzka, K., Duenne, M., Schirmer, M.: Ecophysiological and ecotoxicological aspects of a closed, self-sustaining, aquatic life support system. In: International Conference on Environmental Systems; JUL. 10 (2000)

Strauch, S.M., Schuster, M., Lebert, M., Richter, P., Schmittnägel, M., Häder, D.-P.: A closed ecological system in a Space experiment. In: Ouwehand, L. (ed.) Proceedings of the Symposium Life in Space for Life on Earth: 22 - 27 June 2008, Angers, France. Noordwijk: ESA Communication Production Office 41-42 (2008)

Strauch, S.M.: Euglena gracilis als Sauerstoffproduzent eines bioregenerativen Lebenserhaltungssystems und ihre physiologische Reaktion auf Änderungen der Schwerkraft: (Euglena gracilis as oxygen producer in a bioregenerative life support system and its physiologial reaction on changes of the acceleration level). Dissertation University of erlangen-nürnberg (2009)

Strauch, S.M., Richter, P.R., Schuster, M., Häder, D.-P.: The beating pattern of the flagellum of Euglena gracilis under altered gravity during parabolic flights. J. Plant Physiol. 167(1), 41-6 (2010)
Strauch, S.M., Becker, I., Pölloth, L., Richter, P.R., Haag, F.W.M., Hauslage, J.: Restart capability of resting-states of Euglena gracilis after 9 months of dormancy: Preparation for autonomous space flight experiments. Int. J. Astrobiol. 44, 1-11 (2017)

Streb, C., Richter, P.R., Ntefidou, M., Lebert, M., Hä, d.er., D.-P.: Sensory transduction of gravitaxis in Euglena gracilis. J. Plant Physiol. 159, 855-62 (2002)

Tahedl, H., Richter, P.R., Lebert, M., Häder, D.-P.: cAMP is involved in gravitaxis signal transduction of Euglena gracilis. Micrograv. Sci. Technol. 11, 173-8 (1998)

Tikhomirov, A.A., Ushakova, S.A., Kovaleva, N.P., Lamaze, B., Lobo, M., Lasseur, C.: Biological life support systems for a Mars mission planetary base: Problems and prospects. Adv. Space Res. 40(11), 1741-5 (2007)

Verostko, C.E., Edeen, M.A., Packham, N.J.C.: A Hybrid Regenerative Water Recovery System for Lunar/Mars Life Support Applications. In: International Conference on Environmental Systems; JUL. 12 (1992)

Wheeler, R.M., Mackowiak, C.L., Stutte, G.W., Yorio, N.C., Ruffe, L.M., Sager, J.C.: Crop productivities and radiation use efficiencies for bioregenerative life support. Adv. Space Res. 41(5), 706-13 (2008)

Wheeler, R.M.: Sager, J.C., Crop Production for Advanced Life Support Systems. Purdue University; Purdue e-Pubs (2006)

Wieland, P.O.: Living Together in Space: The Design and Operation of the Life Support Systems on the International Space Station. Marshall Space Flight Center, Alabama (1998) 